\title{
ПРОБЛЕМА МОТИВАЦИИ У ПАЦИЕНТОВ НА АНТИКОАГУЛЯНТНОЙ ТЕРАПИИ В РАБОТЕ ВРАЧА-СТОМАТОЛОГА
}

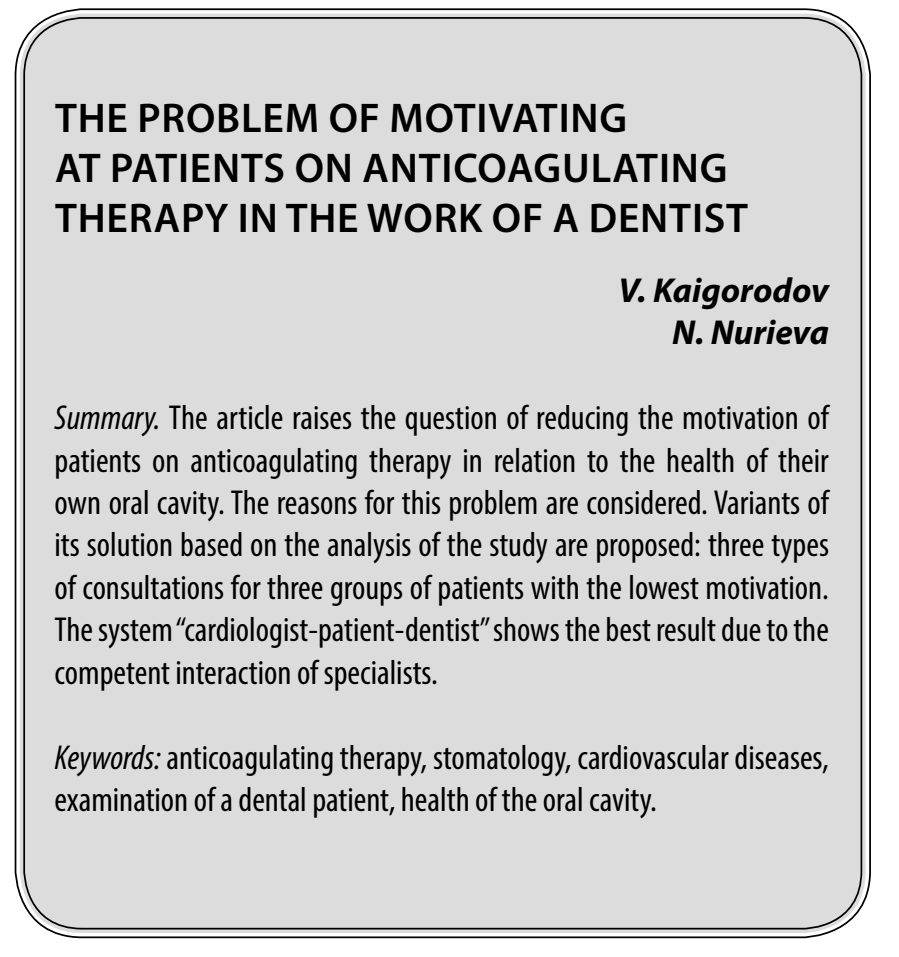

\section{Ввемение}

$\boldsymbol{\Pi}$ ациенты на антикоагулянтной терапии входят в группу с заболеваниями сердечно-сосудистой системы. Их объединяют следующие признаки $[1 ; 6]$ :

- большое количество принимаемых медикаментов;

- посещение медицинских учреждений;

- госпитализация с диагностическими процедурами;

- частая встреча с «белыми халатами»,

- что приводит к стрессу и развитию депрессивного состояния.

Следствием этого являются заторможенность и упадок сил, ограничение физической и социальной активности, ожидание худшего и субъективно негативное отношение к врачу-стоматологу. Последнее выходит из следующих факторов [4]:

- собственный или чужой неудовлетворительный опыт лечения в стоматологии или иных сферах медицины, переносимых на стоматологию;

- отрицательное изображение стоматологии в СМИ;

- страх в стоматологическом кресле.
Кайгородов Вячеслав Александрович

Аспирант, ФГБОУ ВО «Южно-уральский государственный медицинский университет» Минздрава России, г. Челябинск blacknight189006@gmail.com

Нуриева Наталья Сергеевна Д.м.н., профессор, ФГБОУ ВО «Южно-уральский государственный медицинский университет» Минздрава России, г. Челябинск natakipa@mail.ru

Аннотация. В статье поднят вопрос о снижении мотивации пациентов на антикоагулянтной терапии по отношению к здоровью собственной полости рта. Рассмотрены причины данной проблемы. Предложены варианты её решения на основе анализа исследования: три типа консультаций на три группы пациентов, имеющих самую низкую мотивацию. Система «кардиолог-пациент-стоматолог» показывает лучший результат, вследствие грамотного взаимодействия специалистов.

Ключевые слова: антикоагулянтная терапия, стоматология, сердечно-сосудистые заболевания, обследование стоматологического пациента, здоровье полости рта.

На фоне основного сердечно-сосудистого заболевания пациент не считает свой стоматологический статус часто неудовлетворительный - болезнью [8].

Всё это снижает мотивацию больного, осложняет коммуникацию и затрудняет качественный сбор анамнеза, что в работе врача-стоматолога является основополагающим принципом, помогающим лечить не болезнь, но пациента с болезнью.

Учёт вмешивающихся факторов и сопутствующих заболеваний корректирует протокол лечения. Это позволяет справиться с основной задачей и в целом улучшить качество жизни пациента [2;7;9]. Пренебрежение может негативно отразится как на здоровье больного в виде неудовлетворительного результата лечения вплоть до получения критических состояний [10], так и на эмоциональном и физическом состоянии самого врача, что отрицательно скажется на его работе и здоровье [5].

Врач-стоматолог обязан, подключив терпение, психологию и опираясь на знания касательно основного стоматологического и сопутствующего заболеваний, заинтересовать пациента в качестве собственного здоровья, доказать влияние стоматологического статуса 
на статус сердечно-сосудистого заболевания, привлечь к добровольному сотрудничеству и, таким образом, помочь увидеть проблему в новом ракурсе [3].

Целью данного исследования было найти возможное решение в проблеме мотивации пациентов на антикоагулянтной терапии.

\section{Материалы и метолы}

Было отобрано 30 пациентов возрастом (10 мужчин и 20 женщин) на антикоагулянтной терапии, имеющих самую низкую мотивацию для поддержания удовлетворительного уровня здоровья полости рта:

- усталость от врачей и медицинских организаций;

- негативное отношение к стоматологии;

- из анамнеза - отказ от стоматологических вмешательств, кроме случаев острой боли;

Как следствие: неудовлетворительная гигиена полости рта, обширные дефекты и деформации зубных рядов.

Антикоагулянтная терапия включала как варфарин, так и новые оральные антикоагулянты. Пациенты были разделены случайным образом на три группы по 10 человек. В качестве эксперимента было проведено три типа консультаций по одной на каждую группу:

1. Консультация врача-стоматолога, опирающаяся лишь на стоматологические функциональные факторы - дефекты и деформации зубных рядов.

2. Консультация врача-стоматолога, учитывающая сопутствующее заболевание пациента, антикоагулянтную терапию, использование ОПИ объективного пародонтального индекса (патент на изобретение 2655121);

3. Консультация врача-стоматолога и врача-кардиолога;

Исследование проводилось на базе Федерального центра сердечно-сосудистой хирургии г. Челябинска.

Данные обзора литературы получены с электронных peсурсов: eLIBRARY, PubMed.

\section{Результаты исслеАования}

Первый тип подразумевал простую консультацию без учёта сопутствующих заболеваний. Анамнез учитывал срок давности потери зубов и причины. На основе клинического осмотра и обнаружения дефектов и деформаций зубных рядов пациентам были предложены все возможные конструкции - съемные и несъемные - восстанавливающие жевательную эффективность и эстетику. Подобный подход, как и предполагалось, оставил пациентов равнодушными к проблеме. 0\% выразило интерес. Весьма вероятно, что быстрое и сухое перечисление фактов может оттолкнуть ещё больше.

Второй тип подразумевал подробную консультацию. Анамнез учитывал сопутствующие заболевания, в том числе и причины назначения антикоагулянтной терапии, длительность приема препаратов, побочные эффекты в виде кровоточивости десны или носовых кровотечений, частота обращений к стоматологу, частота обращений к кардиологу для коррекции дозировки антикоагулянта или смены плана лечения. Применялся ОПИ - объективный пародонтальный индекс (патент на изобретение 2655121), совмещающий результаты клинического обследования врача и результаты самоанкетирования пациента. Таким образом, создавались элементы «игры», при которой пациент принимал активное участие в диагностике и вовлекался в процесс, познавая собственный организм. 60\% из группы заинтересовались своей проблемой и пообещали заняться здоровьем полости рта, а также обратиться к своему кардиологу в случае обнаружения побочных эффектов.

Третий тип является модификацией второго и дополняется рекомендацией врача-кардиолога о важности наблюдения за здоровьем полости рта. Напоминания о гигиене полости рта, о предупреждении развития заболеваний пародонта и твердых тканей зубов, как профилактики развития бактериального эндокардита у пациентов с сердечно-сосудистыми заболеваниями, особенно с протезированными клапанами сердца, от специалиста иного медицинского профиля оказало колоссальный эффект. Положительный результат от консультации охватил $90 \%$ группы.

\section{Выво $\triangle \mathrm{b}$}

Таким образом, исследование показало не только функциональные, но и этические проблемы.

Узкое мышление специалиста в своём профиле не даёт положительного результата. Это снижает мотивацию и уровень коммуникации пациента. Больному не будет оказана помощь, либо при лечении возрастёт риск неудачи или побочных эффектов.

Индивидуальный и внимательный подход при сборе анамнеза и клиническом обследовании, строящийся на принципах эмпатии, отличает профессиональное поведение от непрофессионального и позволяет объективно выстроить план работы.

Система «стоматолог-пациент-кардиолог» показывает себя наилучшим образом, причём подразумевается её треугольная форма. Пациент, как объект, стоит 
на вершине, специалисты поддерживают основание, имея непрямую связь. Обмен знаниями повышает квалификацию врачей, позволяет грамотно корректировать план лечения относительно общего здоровья больного.
Выстраивается крепкая система «врач-пациент», благодаря которой возможно добровольное сотрудничество, высокая мотивация и, как следствие, положительный результат лечения.

\section{ЛИТЕРАТУРА}

1. Абдувахитова А. Н. Особенности качества жизни у пациентов ХСН пожилого возраста и их психоэмоциональный статус/Абдувахитова А.Н., Абдуллаев Т. А., Цой И. А. // Евразийский кардиологический журнал. - 2017.— № 3.- - 73-74.

2. Алиев А. Н. Психоэмоциональный статус пациентов до лечения зубов. // Достижения науки и образования. — 2018. — № 17(39). — c. 103-104.

3. Вилюжанина Т. А. Психоэмоциональный статус больных стоматологического профиля и его коррекция. // Вестник Денцкого национального университета. Серия Д: Филология и психология.— 2018. — № 3-4.— с. 87-93.

4. Гажва С. И. Психоэмоциональный статус пациентов до и после стоматологического вмешательства. / Гажва С. И., Степанян Т. Б., Горячева Т. П. // Современные проблемы науки и образования.— 2014.— № 4.— с. 296.

5. Денисов А. Эмоциональное выгорание в профессиональной деятельности (на примере эмпирического исследования эмоционального выгорания у стоматологов). / Денисов А., Терёхина Н. // Развитие личности. - 2015.— № 4. - c. 98-112.

6. Крушина О.В. Изменения психоэмоционального статуса и сердечно-сосудистые заболевания: что первично? / Крушина 0. В., Барулин А. Е., Друшлякова А. А. // РМЖ. — 2018. — Т. 26 № 11-1. — c. 32-34.

7. Петров П. И. Исследование психоэмоционального статуса на стоматологическом приеме. / Петров П. И., Еникеев Д. А., Мингазов Г. Г. // Российский стоматологический журнал.— 2012.— № 3.— c. 44-46.

8. Силин А. В. Современный подход к оценке психоэмоционального статуса стоматологических больных. / Силин А. В., Лопушанская Т. А., Коцюбинская Ю. В., Михайлов В. А., Ашнокова И. А. // Институт стоматологии.—2017.— № 4(77). — c. 18-19.

9. Сулейманова 0.0. Изучение психоэмоционального статуса пациентов в предоперационном периоде. / Сулейманова 0. 0., Телицын В.С., Аскеров Э. М., Морозов А. М. // Тверской медицинский журнал. — 2018. — № 2. — c. 94-98.

10. Larsen T.R. et al.: Acute warfarin toxicity: An unanticipated consequence of amoxicillin/clavulanate administration. Am J Case Rep 2014; 15 : 45-48.

๔ Кайгородов Вячеслав Александрович ( blacknight189006@gmail.com ), Нуриева Наталья Сергеевна ( natakipa@mail.ru ).

журнал «Современная наука: актуальные проблемы теории и практики»

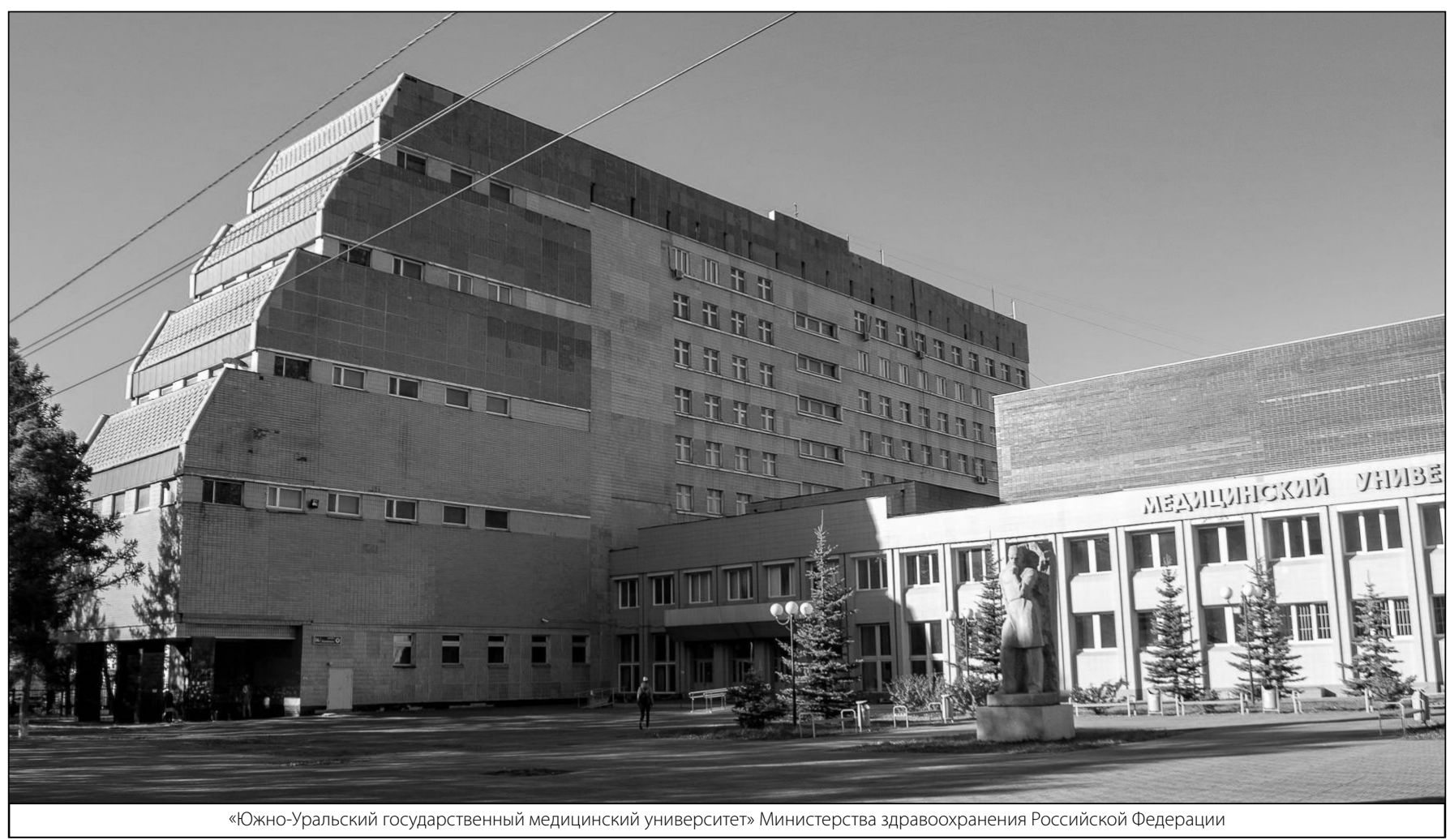

